\title{
Factors Associated with Middle Managers' Work Motivation: Evidence from SMEs in Vietnam
}

\author{
Huong Thanh NGUYEN ${ }^{1}$, Nguyen Danh NGUYEN ${ }^{2}$, Binh Van TRAN ${ }^{3}$
}

Received: August 01, 2020 Revised: October 11, 2020 Accepted: October 15, 2020

\begin{abstract}
This study presents an exploratory investigation of SMEs in Vietnam to understand the impact of personal-level factors on middle managers' work motivation and the moderating role of work environment. A survey of 450 middle managers (MMs) in 150 Hanoi's SMEs was conducted. The findings of this research showed a significant positive impact of Achievement (ACHV), Recognition (RECOG), and Responsibility (RESP) on work motivation of MMs under the investigation. Furthermore, the result indicated that the work environment affects the relationship between personal-level factors and work motivation of participants. Consequently, both work environment improvement and strategies related to personal-level factors need to be taken into consideration. Especially, Recognition and transparency in Responsibility are appreciated in organizations with a low level of work environment satisfaction. However, there were no indications that Participation (PAR) and Communication (CMM) have a considerable impact on work motivation of respondents, being neither low level nor high level of work environment satisfaction. Based on the findings, recommendations are suggested for Vietnam's SMEs to improve work motivation of MMs, by (i) developing standards with emphasis on their achievement, (ii) paying attention to organizational culture focusing on the responsibility of this managerial level, and (iii) building an adequate incentive system, especially non-financial incentives.
\end{abstract}

Keywords: Motivation, Work Environment, Individual Factors, Middle Managers, SMEs

JEL Classification Code: J24, J28, M12, M54

\section{Introduction}

It is widely known that factors influencing work motivation involve both contextual-level and individuallevel factors. Many studies that have dealt with the "why" question of motivation have typically emphasized the effect

${ }^{1}$ First Author. Lecturer, Department of Management and Law, School of Economics and Management, Hanoi University of Science and Technology, Hanoi, Vietnam.

Email: huong.nguyenthanh4@hust.edu.vn

${ }^{2}$ Corresponding Author. Dean, School of Economics and Management, Hanoi University of Science and Technology, Hanoi, Vietnam [Postal Address: No. 1 Dai Co Viet street, Hai Ba Trung district, Hanoi, 100000, Vietnam]

Email: nguyendanhnguyen.hust@gmail.com

${ }^{3}$ Lecturer, Department of Industrial Economics, School of Economics and Management, Hanoi University of Science and Technology, Hanoi, Vietnam. Email: binh.tranvan@hust.edu.vn

(c) Copyright: The Author(s)

This is an Open Access article distributed under the terms of the Creative Commons Attribution Non-Commercial License (https://creativecommons.org/licenses/by-nc/4.0/) which permits unrestricted non-commercial use, distribution, and reproduction in any medium, provided the original work is properly cited. of individual-level factors (Kanfer \& Chen, 2016). There are different ways to motivate people since individuals are different from each other on what is of greater importance to them (Madura, 2007). Numerous observed investigations have revealed that perception of achievement, recognition, responsibility, communication, and participation are leading individual-level factors affecting work motivation (Georgellis et al., 2012; Herzberg, 1965; Jansen \& Samuel, 2014; Lewis, 1972; Shaaban, 2018). Especially, Kominis and Emmanuel (2007) find considerable support that the feeling of accomplishment and recognition are highly desirable rewards all middle managers (MMs) perceive. In relation to $\mathrm{MMs}$, formal and planned communication with senior managers is found to gain perspective about their role and responsibility (Balogun, 2003). Furthermore, in the view of MMs, they attach much significance to participation and involvement. Many scholars criticized the hierarchical and argued for greater autonomy and increased participation in decision-making (Deci \& Vansteenkiste, 2004).

A wide range of incentivizing economic measures are taken into consideration to boost their competition capability and efficiency (Keskgn et al., 2010). Motivation is one of 
the main concerns and an important driver for work success. Motivating employee will help the organization make the best possible use of capital (Ali et al., 2016) since motivated employees with high levels of job involvement will work with more commitment, and eventually increase efficiency (Azar \& Shafighi, 2013). Such results are in line with previous publications which confirmed the positive relationship between factors of motivation and job performance (Aarabi et al., 2013; Pancasila et al., 2020).

Small- and medium-sized enterprises (SMEs) play an important part in the modern economy. In all countries, SMEs have an active role, representing over $90 \%$ of the business population, $60-70 \%$ of employment, and over $55 \%$ of GDP in developed countries (WTO, 2019). In Vietnam, SMEs have been the backbone of the growing economy, accounting for $98 \%$ of all enterprises with approximately, $47 \%$ of the country's GDP (GSO of Vietnam, 2020).

The research conducted by Trinh and Thanh (2017) showed that Vietnam's SMEs have encountered various constraints to their development, including labor utilization. The results also indicated that motivating employees was one of the effective ways to increase labor utilization indicators and business performance. Despite the significance of work motivation, research on the issue is limited in Vietnam. Many studies have sought to uncover the motivation of direct labor (Cuong et al., 2007; Khang, 2014; Larsen et al., 2011), meanwhile, others pay attention to office staff (Khuong \& Hoang, 2015; Swierczek \& Thai, 2003; Thuy \& Nhung, 2018). However, to the date, there is still very little research on work motivation of MMs.

As mentioned above, the study aims (1) to determine factors influencing MMs' work motivation, and (2) to investigate the moderating role of work environment on the relationship between individual needs and motivation of MMs.

\section{Literature Review and Hypothesis}

\subsection{Work Motivation}

There is increasing proof that motivation has played a vital role in human resource management in recent decades. It is generally believed that an organization would rather have motivated and energetic employees than ones with high education, but lacking energy (Kovach, 1987). The large proportion of motivation theories, according to Petri (1996), was focused on diverse approaches to the nature or roots of motivation.

The conventional thinking on motivation dominated over the course of 30 years from 1900 to 1930. This method of conceptualizing motivation is mostly related to Taylor's (1911) philosophy and the scientific school of management.
The fairly mechanistic starting point was that employees usually do not want to work, and are attracted by financial incentives. Consistent with the previous view, Beach (1980) saw motivation as an emotional desire to accomplish a goal or reward. The traditional model made way for the human relations paradigm that prevailed during the period from 1930 to 1960. Mayo (1932) referred to the concept of "social man" who was motivated by social needs, job relationships, and more responsive to working group pressure than to management control (Bruce \& Nyland, 2011). It became popular around the 1960 s to understand motivation in terms of human ability (human resource). The viewpoint maintained that an individual is inspired by something more than just income or fulfilling social interaction, and that especially a sense of accomplishment arising from a productive and demanding job is a powerful desire for workers (Likert, 1967; McGregor, 1960).

In the study, we use the definition of work motivation based on self-determination theory (SDT), which advocates the human resource approach. In SDT, they distinguished between various types of motivation on the basis of particular motives or purposes that lead to action (Deci \& Ryan, 1985). Intrinsic motivation is described, according to Ryan and Deci, as "the doing of an activity for its inherent satisfaction rather than for some separable consequence. When intrinsically motivated, a person is moved to act for the fun or challenge entailed rather than because of external products, pressures or reward". Meanwhile, extrinsic motivation is "a construct that pertains whenever an activity is done in order to attain some separable outcome. Extrinsic motivation thus contrasts with intrinsic motivation, which refers to doing an activity simply for the enjoyment of the activity itself, rather than its instrumental value" (Ryan \& Deci, 2000).

\subsection{Hypothesis Development}

There is rising evidence that work motivation plays a significant role in loyalty (Omar et al., 2010; Spakovska \& Vanek, 2016), organizational productivity (Bawa, 2017; Swart, 2010), interpersonal relationship (Wahyuni et al., 2016), and organizational culture (Yusof et al., 2017). As a result, plenty of studies relating to motivational factors, especially MMs, have been conducted.

Most extensively referred to contemporary theories of motivation related to personal-level factors is SDT, developed by Deci and Ryan(1985). The central postulation of SDT is that people have a psychological need to feel competent, self-determined, and connected (Deci \& Vansteenkiste, 2004). Studies based on SDT indicated that essential factors at the personal level influencing work motivation include a sense of Achievement, Responsibility, Recognition, Communication, and Participation. As a result, the study identified the five main factors including sense of 
Achievement, Responsibility, Recognition, Communication, and Participation, which have considerable influence on middle managers' work motivation by synthesizing previous research and theoretical perspectives.

\section{Achievement}

Achievement is what individuals are inspired to accomplish when they are challenged and conscious that the achievement will be mirrored in their performance. Deci and Ryan's (1985) SDT contributed a solid framework for understanding the construct of individual perceived challenge. A person is challenged when he or she considers the challenges of the activity to be balanced with his or her task performance abilities (Reeve \& Deci, 1996). According to SDT, challenges are essential to facilitate intrinsic motivation (Deci \& Ryan, 1985). Conversely, events that result in feelings of incompetence may undermine intrinsic motivation ( $\mathrm{Li} \& \mathrm{Pan}, 2009$ ). More specifically, in dealing with MMs, Samuel (2014) stated that they perceived feeling of accomplishment appeared to be highly desirable rewards. Consequently, it is found that challenging tasks, the attainability of targets, and the accuracy of performance indicators should be taken into account by reward-system designers. The result finds considerable support with the findings of a study published by Kominis and Emmanuel (2007). Thus, we predict that a sense of achievement will have a positive impact on MMs' motivation.

H1: A sense of achievement has a positive impact on MMs' motivation.

\section{Responsibility}

Dose and Klimoski (1995) defined responsibility as a situation in which a person feels obliged to circumstances or events. Responsibility can be considered an obligation and inner commitment from an individual for the desired fulfillment of all delegated tasks (Bing et al., 2011). A person who is demonstrating personal responsibility is likely to consider how his choices and behavior will impact on others. In other words, he owns the willingness to hold himself accountable for the behavior enacted and the resulting outcomes (Mergler et al., 2007). Adding responsibility for the workers with their regular worker is one of the important features to make workers satisfy to work in the organization, thus enhance the motivational level. Therefore, we predict that a sense of responsibility will have a positive impact on MMs' motivation.

H2: A sense of responsibility has a positive impact on MMs'motivation.

\section{Recognition}

This can be referred to an intrinsic way of getting employee motivation has become an essential phenomenon (Al Harbi et al., 2019). Grawitch and Baber (2010) stated that recognition is not only about the accomplishment of a person's performance, but is more concentrated on contributions and efforts made by employees. In addition, they not only want to feel they are an essential part of the organization's success, but also desire the notice and acknowledgment of their senior and co-workers (Larson \& Hewitt, 2005). Recognition as an intrinsic incentive is recognized because of its values that go hand in hand with the core human values. Regarding MMs, there was a positive correlation between work motivation and recognition (Kumarasinghe \& Hoshino, 2010). The result is consistent with the previous studies (Jansen \& Samuel, 2014; Kominis \& Emmanuel, 2007). Hence, we predict that a sense of recognition will have a positive impact on MMs' motivation.

H3: A sense of recognition has a positive impact on MMs'motivation.

\section{Communication}

Interpersonal communication is the information exchange between individuals who, in personal or nonpersonal contexts, are typically performed face to face (Singh, 2014). In organizations, employees have experience of communication in a wide range of ways. Jo and Shim (2005) indicated that encouraging contact was positively connected to people's views of management's support and friendliness. Addressing the issue of MMs, Westley (1990) pointed out that MMs feel isolated when there is resisted conversation, lack of formal or informal channels for MMs to interfunctionally interact, or where general strategic dialogues are confined to the high ranking group. As a result, effective two-way communication is supposed to be formed to increase the motivational level. In the study, we predict that a sense of communication will have a positive impact on MMs' motivation.

H4: A sense of communication has a positive impact on MMs'motivation.

\section{Participation}

In organizations, employees especially middle management have a desire of being actively involved in goal setting, policy formation, and top decision making. Besides, employees' need for participation also manifests itself in being allowed a certain amount of discretion and freedom of choice in decisions concerning their work. 
When individuals are involved in a mission, they see more commitment as leading to greater mastery and competence (Deci \& Ryan, 1985). With respect to MMs, Nilakant and Ramnarayan (1990) indicated that they expected to deal with top decisions. According to this view, lack of control and autonomy over work execution and decision-making process are the main demotivational factors. Thus, we predict that a sense of participation will have a positive impact on MMs' motivation.

H5: A sense of participation has a positive impact on MMs'motivation.

\section{Moderator and control variable}

Work environment has an effect on employees' perception of an organization (Nguyen et al., 2019). As a result, a work environment with a high level of satisfaction is likely to motivate employees in general and middle managers in particular. Furthermore, work enviroment also affects the relationship between personal-level factors and work motivation (De Hoogh et al., 2005). Noticeably, different types of companies and experience also have a considerable impact on the work motivation of employees. Consequently, the current study examines the moderating role of work environment variables as well as several control variables including gender, experience. Thus, the authors propose the following hypotheses:

H6: Work environment has a moderating effect on the relationship between personal-level factors and $M M s^{\prime}$ motivation.

H7: Experience, industry, and gender have an impact on MMs'motivation.

\section{Research Methods and Materials}

\subsection{Development of Survey Instrument}

We used a structured questionnaire to collect and analyze the data by survey method. The constructs used in the research model were adapted from the literature and previous studies (Deci \& Ryan, 1985; Jansen \& Samuel, 2014; Kominis \& Emmanuel, 2007). The items that evaluate each construct used in the model were referenced from other studies. Specifically, work motivation (MOV) construct was measured by six items based upon from Broek et al. (2010). ACHV construct was evaluated by five items and adapted from Lang and Fries (2006). RESP construct was measured by two items that developed from Kumarasinghe and Yasuo (2010). RECOG construct was assessed by six items adapted from Sonawane (2008). CMM construct was measured by five items based upon Ramirez (2010) and the PAR construct was evaluated by three items adapted from Kumarasinghe and Yasuo (2010) (Kumarasinghe \& Hoshino, 2010; Lang \& Fries, 2006; Ramirez, 2012; Sonawane, 2008; Van den Broeck et al., 2010). The items used for evaluating the constructs in the model were translated from English to Vietnamese, and using the backtranslation method to ensure the reliability and concordance of the translation process. The questionnaire was adjusted through discussing with five experts in human resource management from the companies and universities in Hanoi (Hanoi University of Science and Technology and National Economics University). All items were measured by a five-point Likert scale (1: strongly disagree and 5: strongly agree). The items of each construct in the model are described in Table 1.

\subsection{Sample and Data Collection}

The survey subjects were the middle managers of SMEs in Hanoi, the largest economic area in the North of Vietnam. The sample size was determined to be 400 respondents, which is very good for quantitative research (Comrey \& Lee, 1992). Survey data was collected in 2018 and 2019 with the support of the Department of Industry and Trade, and the Department of Planning and Investment in Hanoi through business conferences for SMEs. We distributed 500 questionnaires and collected 425 valid questionnaires - a response rate of $85 \%$. The characteristics of companies are described in Table 2.

\subsection{Data Analysis Method}

We used the multivariate data analysis method to analyze survey data and test the proposed hypotheses. Specifically, we test the reliability of items in the constructs by Cronbach's Alpha coefficient and exploratory factor analysis (EFA). The criteria were chosen including the Cronbach's Alpha coefficients were larger than 0.7 and corrected item-total correlations of each construct were larger than 0.3 (Nunnally, 1994). In EFA analysis, the criteria were KMO coefficient is larger than 0.5, the p-value of Bartlett's test is less than 0.05, the factor loadings of the items in each construct are 0.5 , and total variance explained (TVE) is larger than 50\% (Hair et al., 2010). Next, the confirmatory factor analysis (CFA) is used to evaluate the model fit with the actual data and tests the validity of each construct in the model. The criteria of CFA include CFI, TLI, and IFI coefficients are larger than 0.9, RMSEA is less than 0.08 (Kline, 2011) showing that the research model reaches the overall fit index. The factor loading of items in CFA analysis is larger than 0.6 present that the constructs achieved the convergent validity (Hair et al., 2010). In order to assess the discriminant validity of each construct, we used the square root of average variance extracted (AVE) comparing with the correlations among the constructs in the model. 
Table 1: The items of each construct in the research model

\begin{tabular}{|c|c|c|}
\hline Constructs/ltems & Statement & References \\
\hline \multicolumn{3}{|l|}{ Work motivation } \\
\hline MOV1 & Because I have fun doing my job. & \multirow{6}{*}{$\begin{array}{l}\text { Broeck et al. } \\
(2010)\end{array}$} \\
\hline MOV2 & Because I personally consider it important to put efforts in this job. & \\
\hline MOV3 & Because putting efforts in this job aligns with my personal values. & \\
\hline MOV4 & Because I have to prove to myself that I can. & \\
\hline MOV5 & Because otherwise I will feel bad about myself. & \\
\hline MOV6 & Because I risk losing my job if I don't put enough effort in it. & \\
\hline \multicolumn{3}{|l|}{ Achievement } \\
\hline $\mathrm{ACHV} 1$ & I enjoy situations, in which I can make use of my abilities. & \multirow{5}{*}{$\begin{array}{l}\text { Lang \& Fries } \\
(2006)\end{array}$} \\
\hline $\mathrm{ACHV} 2$ & $\begin{array}{l}\text { I prefer to know how I am progressing and to obtain concrete feedback when } \\
\text { working at a task. }\end{array}$ & \\
\hline ACHV3 & $\begin{array}{l}\text { I prefer to know how I am progressing and to obtain concrete feedback when } \\
\text { working at a task. }\end{array}$ & \\
\hline ACHV4 & $\begin{array}{l}\text { While working on a task, I think of how it will feel when and if the task is } \\
\text { successfully completed. }\end{array}$ & \\
\hline ACHV5 & I feel uneasy to do something if I am not sure of succeeding. & \\
\hline \multicolumn{3}{|l|}{ Responsibility } \\
\hline RESP1 & I am willing to take responsibility for my own work assignment. & \multirow{2}{*}{$\begin{array}{l}\text { Kumarasinghe } \\
\& \text { Yasuo (2010) }\end{array}$} \\
\hline RESP2 & I expect to be given special assignments for more difficult tasks. & \\
\hline \multicolumn{3}{|l|}{ Recognition } \\
\hline RECOG1 & I deeply cherish all the recognition received in organization. & \multirow{6}{*}{$\begin{array}{l}\text { Sonawane } \\
(2008)\end{array}$} \\
\hline RECOG2 & Recognition provided by my organization is adequate to my efforts. & \\
\hline RECOG3 & Recognition provided by my organization is timely. & \\
\hline RECOG4 & Formal recognition provided by my organization is important to me. & \\
\hline RECOG5 & $\begin{array}{l}\text { Informal recognition (personal praise, special mention in a meeting, etc.) } \\
\text { provided by my organization is important to me. }\end{array}$ & \\
\hline RECOG6 & Recognition is important as long as it is monetary in nature. & \\
\hline \multicolumn{3}{|l|}{ Communication } \\
\hline CMM1 & I am willing to listen and pay attention to my subordinates & \multirow{5}{*}{$\begin{array}{l}\text { Ramirez } \\
(2010)\end{array}$} \\
\hline CMM2 & I clear up queries of my subordinates in a timely manner & \\
\hline CMM3 & $\begin{array}{l}\text { I put more effort if I have an opportunity to share my ideas and experience } \\
\text { with the superior }\end{array}$ & \\
\hline CMM4 & I put more effort if I receive timely feedback from the superior & \\
\hline CMM5 & $\begin{array}{l}\text { I put more effort if I receive transparent feedback from the } \\
\text { superior }\end{array}$ & \\
\hline \multicolumn{3}{|l|}{ Participation } \\
\hline PAR1 & I put more effort if I am a part of strategic planning process & \multirow{3}{*}{$\begin{array}{l}\text { Kumarasinghe } \\
\& \text { Yasuo (2010) }\end{array}$} \\
\hline PAR2 & I put more effort if I am involved in policy formation and decision making & \\
\hline PAR3 & $\begin{array}{l}\text { I put more effort if I am allowed a certain amount of discretion and freedom } \\
\text { of choice in decision concerning my work. }\end{array}$ & \\
\hline
\end{tabular}


Table 2: Profile of companies

\begin{tabular}{|c|c|c|}
\hline \multicolumn{2}{|l|}{ Categorical } & Frequency (\%) \\
\hline \multirow{2}{*}{ Gender } & Males & $213(50.1 \%)$ \\
\hline & Females & $212(49.9 \%)$ \\
\hline \multirow{5}{*}{ Age } & $18-22$ years & $29(6,8 \%)$ \\
\hline & $23-30$ years & $89(20,9 \%)$ \\
\hline & $31-40$ years & $227(53,4 \%)$ \\
\hline & $41-50$ years & $73(17,2 \%)$ \\
\hline & 50 or more years & $7(1,6 \%)$ \\
\hline \multirow{4}{*}{ Education } & Bachelor & $290(68,2 \%)$ \\
\hline & Master & $118(27,8 \%)$ \\
\hline & Doctoral & $5(1,2 \%)$ \\
\hline & Others & $12(2,8 \%)$ \\
\hline \multirow{4}{*}{ Seniority } & $<3$ years & $82(19,3 \%)$ \\
\hline & $3-5$ years & $100(23,5 \%)$ \\
\hline & $5-10$ years & $143(33,6 \%)$ \\
\hline & $>10$ years & $100(23,5 \%)$ \\
\hline \multirow{4}{*}{$\begin{array}{l}\text { Managerial } \\
\text { position }\end{array}$} & Head of department & $234(55,1 \%)$ \\
\hline & Deputy of department & $94(22,1 \%)$ \\
\hline & Team leader & $47(11,1 \%)$ \\
\hline & Others & $50(11,8 \%)$ \\
\hline \multirow{4}{*}{$\begin{array}{l}\text { Types of } \\
\text { ownership } \\
\text { structures }\end{array}$} & $\begin{array}{l}100 \% \text { State Owned- } \\
\text { enterprises }\end{array}$ & $18(4,2 \%)$ \\
\hline & State Owned- enterprises & $8(1,9 \%)$ \\
\hline & Private & $393(92,5 \%)$ \\
\hline & Others & $6(1,4 \%)$ \\
\hline \multirow{4}{*}{ Industry } & $\begin{array}{l}\text { Agriculture, Forestry, } \\
\text { Fishing }\end{array}$ & $2(0,5 \%)$ \\
\hline & Industry and Construction & $140(32,9 \%)$ \\
\hline & Trade and Service & $230(54,1 \%)$ \\
\hline & Others & $53(12,5 \%)$ \\
\hline
\end{tabular}

If, the square root of AVEs is larger than the correlations between the construct indicating the constructs reach the discriminant validity. To evaluate the reliability of constructs we use the composite coefficients and AVE. If the composite coefficients are larger than 0.6 and AVEs larger than 0.5 showing the constructs are reliable (Hair et al., 2010). To test the proposed hypotheses, we use a structural equation model. We conduct three models (full sample, low score environment, and high score environment). The value is used to divide data into two groups (high-low) being the value median of environment construct. In order to consider the moderator role of the environment construct on the relationship between individual factors and work motivation, we used the Chisquare test at statistically significant at $5 \%$.

\section{Results and Discussion}

\subsection{Reliability and Validity}

The analysis results indicated that the constructs in the model achieved the reliability of scales. The Cronbach's Alpha coefficients of each construct were lager than 0.7, which showed the items measured the constructs reaching internal consistency within each construct. EFA analysis result showed that the KMOs were larger than 0.5, Bartlett's test had a p-value of less than 0.05 , the factor loadings of items in each construct were larger than 0.5 , and the variance explained was larger than $50 \%$ (Table 3 ).

\section{Confirmatory factor analysis}

CFA analysis result presented that the model achieved the overall fit with the actual data: $\mathrm{CFI}=0.914, \mathrm{GFI}=$ $0.879, \mathrm{TLI}=0.889, \mathrm{IFI}=0.945$. The factor loadings of items in each construct were larger than 0.6 showing that the items used in the constructs reached convergent validity. The composite reliability coefficients were larger than 0.7 , and average variance was larger than $50 \%$ showing that the constructs in the model were reliable with official data (Table 4).

Table 3: The test of reliability

\begin{tabular}{|l|c|c|c|c|c|}
\hline Constructs & KMO & p-value & Factor loadings range & Variance explained (\%) & Cronbach's Alpha \\
\hline Motivation & 0.780 & 0.000 & $0.778-0.808$ & 63.571 & 0.808 \\
\hline Achievement & 0.707 & 0.000 & $0.842-0.908$ & 60.616 & 0.749 \\
\hline Recognition & 0.711 & 0.000 & $0.648-0.818$ & 56.587 & 0.797 \\
\hline Communication & 0.763 & 0.000 & $0.763-0.902$ & 67.248 & 0.877 \\
\hline Responsibility & 0.500 & 0.000 & $0.902-0.902$ & 81.311 & 0.762 \\
\hline Participation & 0.639 & 0.000 & $0.763-0.942$ & 77.601 & 0.851 \\
\hline Environment & 0.738 & 0.000 & $0.762-0.862$ & 64.414 & 0.836 \\
\hline
\end{tabular}


Huong Thanh NGUYEN, Nguyen Danh NGUYEN, Binh Van TRAN /

Table 4: The CFA analysis result, composite reliability and average variance extracted

\begin{tabular}{|l|c|c|c|}
\hline Construct & Factor loadings range (CFA) & Composite reliability & Average variance extracted \\
\hline Motivation & $0.650-0.750$ & 0.807 & 0.513 \\
\hline Achievement & $0.735-0.855$ & 0.861 & 0.676 \\
\hline Recognition & $0.703-0.879$ & 0.806 & 0.677 \\
\hline Communication & $0.601-0.950$ & 0.895 & 0.687 \\
\hline Participation & $0.892-0.953$ & 0.942 & 0.890 \\
\hline Responsibility & $0.708-0.884$ & 0.779 & 0.641 \\
\hline Model fit index & CFI $=0.914, \mathrm{GFI}=0.879, \mathrm{TLI}=0.889, \mathrm{FI}=0.945$ RMSEA $=0.071$. \\
\hline
\end{tabular}

Table 5: Result of discriminant validity test

\begin{tabular}{|l|c|c|c|c|c|c|c|}
\hline Construct & Mean (SD) & Mov & Achv & Recog & Comm & Par & Resp \\
\hline Motivation & $3.920(0.532)$ & 0.716 & & & & & \\
\hline Achievement & $3.514(0.733)$ & 0.678 & 0.822 & & & & \\
\hline Recognition & $3.898(0.532)$ & 0.619 & 0.684 & 0.823 & & & \\
\hline Communication & $3.804(0.656)$ & 0.603 & 0.676 & 0.726 & 0.829 & & \\
\hline Participation & $3.931(0.637)$ & 0.343 & 0.457 & 0.376 & 0.394 & 0.943 & \\
\hline Responsibility & $3.823(0.618)$ & 0.644 & 0.621 & 0.610 & 0.736 & 0.661 & 0.800 \\
\hline
\end{tabular}

Table 6: The SEM analysis result

\begin{tabular}{|c|c|c|c|c|c|}
\hline \multirow{2}{*}{\multicolumn{3}{|c|}{ Relationships }} & \multicolumn{3}{|c|}{ Std. Beta (critical ratio) } \\
\hline & & & \multirow{2}{*}{$\begin{array}{c}\text { Full Sample }(\mathbf{n}=\mathbf{4 2 5}) \\
0.413(5.345)^{* *}\end{array}$} & \multirow{2}{*}{\begin{tabular}{|l|} 
Low $(\mathbf{n}=185)$ \\
$0.253(2.627)^{\star}$
\end{tabular}} & \multirow{2}{*}{$\frac{\text { High }(n=240)}{0.523(3.907)^{\star *}}$} \\
\hline Achievement & $\rightarrow$ & MOV & & & \\
\hline Recognition & $\rightarrow$ & MOV & $0.204(3.054)^{*}$ & $0.287(2.384)^{*}$ & $0.073(0.688)$ \\
\hline Communication & $\rightarrow$ & MOV & $-0.010(-0.122)$ & $0.001(0.010)$ & $0.052(0.508)$ \\
\hline Responsibility & $\rightarrow$ & MOV & $0.241(3.904)^{* *}$ & $0.559(2.366)^{*}$ & $0.225(2.372)^{*}$ \\
\hline Participation & $\rightarrow$ & MOV & $-0.092(-1.745)$ & $-0.205(-1.465)$ & $-0.136(-1.944)$ \\
\hline Industry & $\rightarrow$ & MOV & $-0.141(3.373)^{\star *}$ & $-0.065(-1.009)$ & $-0.164(-2.996)^{*}$ \\
\hline Gender & $\rightarrow$ & MOV & $0.057(1.402)$ & $0.159(2.445)^{*}$ & $0.013(0.256)$ \\
\hline Experience & $\rightarrow$ & MOV & $-0.027(-0.665)$ & $-0.030(-0.462)$ & $0.013(0.247)$ \\
\hline Model fit index & & & $\begin{array}{c}\mathrm{CFI}=0.928, \mathrm{GFI}=0.919 \\
\mathrm{IFI}=0.929 \\
\mathrm{RMSEA}=0.087\end{array}$ & $\begin{array}{c}\mathrm{CFI}=0.853 \\
\mathrm{GFI}=0.862, \mathrm{IFI}=0.856 \\
\mathrm{RMSEA}=0.121\end{array}$ & $\begin{array}{c}\mathrm{CFI}=0.929 ; \mathrm{GFI}=0.909 \\
\mathrm{IFI}=0.930 \\
\mathrm{RMSEA}=0.089\end{array}$ \\
\hline
\end{tabular}

Notes: ${ }^{*} p<0.05 ;{ }^{*} p<0.01$

\section{Discriminant validity}

To test the discriminant validity among the construct, we compared the square root of AVEs and the correlation coefficients of the paired constructs in the model. The findings showed that the value of the square root of AVEs were the correlation coefficients of constructs in the model. This indicated that the constructs reached discriminant validity (Table 5).

\subsection{Structural Model}

The structural equation modeling (SEM) was utilized to test the proposed hypotheses with three models. The estimation result from the data surveyed was described in Table 6.

The estimation result indicated that TT, GN, and TN have a positive impact on the work motivation of middle 
manager of SMEs $(\beta>0$, p-value $<0.05)$, meanwhile, GT and TN were insignificant at 0.05 ( $\mathrm{p}$-value $>0.05$ ). Thus, the hypotheses $\mathrm{H} 1, \mathrm{H} 2, \mathrm{H} 3$ were accepted, and $\mathrm{H} 4$ and $\mathrm{H} 5$ were rejected.

The findings also showed that only the industry variable had an impact on work motivation. Using Chi-square test to choose the invariant model and variant model showed that: $\Delta$ Chi-square $=15$ and $\Delta \mathrm{df}=7$ and $\mathrm{p}$-value $=0.033<0.05$ ). This indicated that using the variant model is better than the invariant model. In other words, work environment is a moderator variable in the relationships between other work factors and work motivation of MMs in SMEs. Therefore, hypothesis $\mathrm{H} 6$ was accepted, $\mathrm{H} 7$ was partially accepted.

\subsection{Discussion}

The key objective of this study is to discover the influence of personal-level factors on work motivation and the moderator role of work environment. Based on the results of the research, the impact of different factors, characteristics of individuals, and enterprises on work motivation were examined. In addition, the study illustrates how work environment plays the moderator role in the relationship between personal-level factors and work motivation.

The most significant finding is the positive impact of Achievement (ACHV), Recognition (RECOG), and Responsibility (RESP) on work motivation. Our results point out that formal and informal recognition, challenges and difficulties in achievement, and a sense of responsibility are significant to MMs' motivation. MMs are accountable to top management for their department's function since they are communicators between the top-level managers and the lowest level of operational staff. Besides, achievement and recognition are generally believed to be the most convincing evidence of one's ability in his organization. Noticeably, these two factors are considered a signal about one's ability, which serves as the indirect transmission sent to the job market when considering an opportunity in another organization (Tran \& Do, 2020). This finding is in line with previous studies in various markets and fields, such as educational psychology (Hiebert, 2010), human migration (Mulder \& Van Ham, 2005).

According to collected data concerning work environment, the study also indicated that Achievement, Recognition, and a sense of Responsibility influence MMs' work motivation at different levels. To be more precise, Achievement has a greater influence on the work motivation of MMs with a higher level of work environment satisfaction $(\beta=0,523)$ than peers with a lower level of work environment satisfaction $(\beta=0,253)$. Meanwhile, Recognition and a sense of Responsibility show a stronger effect on work motivation of MMs with a lower level of work environment satisfaction. This finding implies that MMs pay little attention to the
Achievement aspect, whereas Recognition and transparency in Responsibility are appreciated in organizations with a low level of work environment satisfaction.

In the current study, personal-level factors show a diverse impact on work motivation in different work environments. It implies the moderating role of work environment on the relationship between personal-level factors and work motivation. Consequently, the result matches our prediction of the hypothesis that MMs in different work environments are influenced by personal level factors at different levels.

Our observations differ most notably from previous research, which indicated a considerable effect of Participation and Communication on MMs' work motivation (O’Neil, 2017; Venkatesh \& Sharma, 2015). The difference may result from the features of SMEs in which Participation and Communication play a minor part in work motivation of MMs. Due to a moderate scale, the communication process between managers and employees in SMEs is faster, easier, and more direct which makes the working relationship closer than in large businesses. MMs are involved in strategic decisions in the same manner. Not only the simple structure but also the direct communication makes the participation of top managers or business owners and MMs in the strategic planning process much easier. Another reason is that organizational culture in SMEs tends to be similar to family culture. It results in a lower power distance relationship between managers and employees.

The analysis reveals the difference in the impact of demographic variables and business characteristics on MMs' work motivation. Specifically, group of business and service industry has a lower motivational level $(\beta=-0.141$, $p$-value $<0.05$ ), especially in enterprises with a high level of work environment satisfaction $(\beta=-0.164$, p-value $<0.05)$. It is noticeable that male managers reveal a higher motivational level in enterprises with a low level of work environment satisfaction. It implies that females tend to be more susceptible than males to the impact of their surroundings. Furthermore, there is a difference in work motivation in different industries. However, the current study provides no evidence for the influence of experience on MMs' work motivation.

\subsection{Recommendations}

From the findings, the authors propose the following suggestions for SMEs' top managers to improve work motivation of MMs: first, it is proposed to develop standards for MMs focusing on their achievement. Also, in order to motive MMs, a KPI system relating to performance in a direct way needs to be taken into account. Besides, another effective way is utilizing financial rewards to encourage, not only MMs, but also their team/group's members. Second, business owners should attach much 
importance to organizational culture placing an emphasis on the responsibility of employees in general and MMs in particular. Consequently, it is necessary to develop programs of training, recruiting, and building organizational culture. Third, the authors suggest an adequate incentive system, especially non-financial incentives, such as honors recognition ceremony, traditional days celebrating for the excellent contribution, etc.

However, the findings of this study have to be seen in light of some limitations. First, convenience sampling is likely to be vulnerable to selection bias and influence beyond the control of researchers, which may not produce representative results. Second, the study carried out inside Hanoi can pose potential problems due to the distinction of the political, economic, and cultural center of the country. Consequently, future research could examine a larger sample size and area of investigation.

\section{Conclusions}

In summary, through a set of data collected from 450 middle managers in 150 SMEs, the authors analyzed the impact of personal-level factors on MMs' work motivation and the moderating role of work environment. Empirical results from SEM analysis show the positive impact of Achievement, Recognition, and Responsibility on work motivation of middle managers. In addition, these factors affect MMs' work motivation at different levels in different work environments. The research result of this article can facilitate the understanding of how to enhance work motivation of MMs in Vietnam's SMEs.

\section{References}

Aarabi, M. S., Subramaniam, I. D., \& Akeel, A. B. A. A. B. (2013). Relationship between motivational factors and job performance of employees in Malaysian service industry. Asian Social Science, 9(9), 301.

Al Harbi, J. A., Alarifi, S., \& Mosbah, A. (2019). Transformation leadership and creativity. Personnel Review.

Ali, A., Bin, L. Z., Piang, H. J., \& Ali, Z. (2016). The impact of motivation on the employee performance and job satisfaction in it park (software house) sector of Peshawar, Pakistan. International Journal of Academic Research in Business and Social Sciences, 6(9), 297-310.

Azar, M., \& Shafighi, A. A. (2013). The effect of work motivation on employees' job performance (Case study: employees of Isfahan Islamic Revolution Housing Foundation). International Journal of Academic Research in Business and Social Sciences, 3(9), 432 .

Balogun, J. (2003). From blaming the middle to harnessing its potential: Creating change intermediaries. British Journal of Management, 14(1), 69-83.
Bawa, M. (2017). Employee motivation and productivity: a review of literature and implications for management practice. International Journal of Economics, Commerce and Management, 12, 662-673.

Bing, M., Donglai, L., \& Zhongmin, L. (2011). Research on relationship between the knowledge-based workers' sense of responsibility and job performance. International Conference on Information and Business Intelligence,

Bruce, K., \& Nyland, C. (2011). Elton Mayo and the deification of human relations. Organization Studies, 32(3), 383-405.

Comrey, A., \& Lee, H. (1992). A First Course in Factor Analysis (2nd ed.). Hillsdale, NJ: Lawrence Earlbaum Associates.

Cuong, T. T., Sang, L., \& Anh, N. (2007). Vietnam's small and medium sized enterprises development: Characteristics, constraints and policy recommendations. SME in Asia and Globalization, ERIA Research Project Report, 5, 323-364.

De Hoogh, A. H., Den Hartog, D. N., \& Koopman, P. L. (2005). Linking the Big Five-Factors of personality to charismatic and transactional leadership; perceived dynamic work environment as a moderator. Journal of Organizational Behavior: The International Journal of Industrial, Occupational and Organizational Psychology and Behavior, 26(7), 839-865.

Deci, E., \& Ryan, R. (1985). Intrinsic motivation and selfdetermination in human behavior. Springer Science \& Business Media.

Deci, E. L., \& Vansteenkiste, M. (2004). Self-determination theory and basic need satisfaction: Understanding human development in positive psychology. Ricerche Di Psicologia, 27(1), 23-40.

Dose, J. J., \& Klimoski, R. J. (1995). Doing the right thing in the workplace: Responsibility in the face of accountability. Employee Responsibilities and Rights Journal, 8(1), 35-56.

Georgellis, Y., Lange, T., \& Tabvuma, V. (2012). The impact of life events on job satisfaction. Journal of Vocational Behavior, 80(2), 464-473.

Grawitch, M. J., \& Barber, L. K. (2010). Work flexibility or nonwork support? Theoretical and empirical distinctions for work-life initiatives. Consulting Psychology Journal: Practice and Research, 62(3), 169.

GSO of Vietnam. (2020). Press release of White Book on Vietnamese Businesses 2020. Retrieved July 15, 2020 from https://gso.gov. vn/default.aspx?tabid=382\&idmid=2\&ItemID=19594

Hair, J. F., Black, W. C., Babin, B. J., \& Anderson, R. E. (2010). Multivariate Data Analysis: A Global Perspective (7th ed.). London, UK: Pearson Education.

Herzberg, F. (1965). The motivation to work among Finnish supervisors. Personnel Psychology, 18(4), 393-402.

Hiebert, B. (2010). Comprehensive guidance and counseling in the schools: Career-life planning for all. Keynote presentation to the annual conference of the Portuguese Association for Career Development. Minho, Portugal,

Jansen, A., \& Samuel, M. O. (2014). Achievement of organisational goals and motivation of middle level managers within the 
context of the two-factor theory. Mediterranean Journal of Social Sciences, 5(16), 53-53.

Jo, S., \& Shim, S. W. (2005). Paradigm shift of employee communication: The effect of management communication on trusting relationships. Public Relations Review, 31(2), 277-280.

Kanfer, R., \& Chen, G. (2016). Motivation in organizational behavior: History, advances and prospects. Organizational Behavior and Human Decision Processes, 136, 6-19.

Keskġn, H., Ġentürk, C., Sungur, O., \& Kg̈rg்g, H. M. (2010). The importance of SMEs in developing economies. 2nd International Symposium on Sustainable Development,

Khang, D. D. N. (2014). A study on factors affecting employee motivation in Vinamilk Can Tho company. International University HCMC, Vietnam.

Khuong, M. N., \& Hoang, D. T. (2015). The effects of leadership styles on employee motivation in auditing companies in Ho Chi Minh City, Vietnam. International Journal of Trade, Economics and Finance, 6(4), 210.

Kline, R. B. (2011). Principles and practice of structural equation modeling (3rd ed.). New York, NY: Guilford Press.

Kominis, G., \& Emmanuel, C. R. (2007). The expectancy-valence theory revisited: Developing an extended model of managerial motivation. Management Accounting Research, 18(1), 49-75.

Kovach, K. A. (1987). What motivates employees? Workers and supervisors give different answers. Business Horizons, 30(5), 58-65.

Kumarasinghe, S., \& Hoshino, Y. (2010). The role and perceptions of middle managers and their influence on business performance: The case of Sri Lanka. International Business Research, 3(4), 3-16.

Lang, J. W., \& Fries, S. (2006). A revised 10-item version of the Achievement Motives Scale. European Journal of Psychological Assessment, 22(3), 216-224.

Larsen, A. F., Rand, J., \& Torm, N. (2011). Do recruitment ties affect wages? An analysis using matched employer-employee data from Vietnam. Review of Development Economics, 15(3), 541-555.

Larson, S. A., \& Hewitt, A. S. (2005). Staff recruitment, retention, \& training strategies for community human services organizations. Baltimore, MD: Paul H. Brookes Pub. Co.

Lewis, R. B. (1972). Motivation model for extension. Journal of Extension, 10(4), 23-34.

Li, P., \& Pan, G. (2009). The Relationship between Motivation and Achievement-A Survey of the Study Motivation of English Majors in Qingdao Agricultural University. English Language Teaching, 2(1), 123-128.

Likert, R. (1967). The human organization: its management and values. New York, NY: McGraw-Hill.

Madura, J. (2007). Introduction to business (4th ed.). Cincinnati, $\mathrm{OH}$ : South-Western College Pub.
McGregor, D. (1960). The human side of enterprise. New York, NY: McGraw-Hill.

Mergler, A. G., Spencer, F. H., \& Patton, W. A. (2007). Development of a measure of personal responsibility for adolescents. Journal of Adolescence, 27.

Mulder, C. H., \& Van Ham, M. (2005). Migration histories and occupational achievement. Population, Space and Place, 11(3), 173-186.

Nguyen, H. M., Mai, L. T., \& Huynh, T. L. (2019). The role of transformational leadership toward work performance through intrinsic motivation: A study in the Pharmaceutical field in Vietnam. Journal of Asian Finance, Economics and Business, 6(4), 201-212. https://doi.org/10.13106/jafeb.2019.vol6. no4.201

Nilakant, V., \& Ramnarayan, S. (1990). Manager in the Middle: A Case of Underdevelopment and Underutilization. Vikalpa, 15(2), 3-12.

Nunnally, J. C. (1994). Psychometric theory (3 ${ }^{\text {rd }}$ ed.). New York, NY: Tata McGraw-Hill education.

O'Neil, J. J. (2017). Developing middle managers in the Hong Kong Public sector: a critique of leadership development from a labour process perspective. Edinburgh Napier University.

Omar, M. W., Jusoff, K., \& Hussin, H. (2010). Employee motivation and its impact on employee loyalty. World Applied Sciences Journal, 8(7), 871-873.

Pancasila, I., Haryono, S., \& Sulistyo, B. A. (2020). Effects of Work Motivation and Leadership toward Work Satisfaction and Employee Performance: Evidence from Indonesia. Journal of Asian Finance, Economics and Business, 7(6), 387-397. https:// doi.org/10.13106/jafeb.2020.vol7.no6.387

Petri, H. L. (1996). Motivation: Theory, research, and applications (4th ed.). Boston, MA: Thomson Brooks/Cole Publishing Co.

Ramirez, D. L. (2012). Organizational communication satisfaction and job satisfaction within university foodservice. Kansas State University.

Reeve, J., \& Deci, E. L. (1996). Elements of the competitive situation that affect intrinsic motivation. Personality and Social Psychology Bulletin, 22(1), 24-33.

Ryan, R. M., \& Deci, E. L. (2000). Intrinsic and extrinsic motivations: Classic definitions and new directions. Contemporary Educational Psychology, 25(1), 54-67.

Samuel, R. (2014). The gendered interplay between success and well-being during transitions. Educational Research, 56(2), 202-219.

Shaaban, S. (2018). The Impact of Motivation on Organisational Citizenship Behaviour (OCB): The Mediation Effect of Employees' Engagement. Journal of Human Resource Management, 6(2), 58-66.

Singh, A. K. (2014). Role of interpersonal communication in organizational effectiveness. International Journal of Research in Management and Business Studies, 1(4). 
Huong Thanh NGUYEN, Nguyen Danh NGUYEN, Binh Van TRAN /

Journal of Asian Finance, Economics and Business Vol 7 No 11 (2020) 1009-1019

Sonawane, P. (2008). Non-monetary rewards: Employee choices \& organizational practices. Indian Journal of Industrial Relations, 44(2), 256-271.

Spakovska, K., \& Vanek, M. (2016). Influence of motivation on work performance and loyalty of employees in industrial enterprises. SGEM2015 Conference Proceedings, 1(3), 399406.

Swart, R. (2010). The influence of employee motivation on productivity in a merged real estate environment. North-West University.].

Swierczek, F. W., \& Thai, T. H. (2003). Motivation, entrepreneurship and the performance of SMEs in Vietnam. Journal of Enterprising Culture, 11(01), 47-68.

Thuy, T. T. P., \& Nhung, T. T. B. (2018). Factors affecting work motivation of office workers - a study in Ho Chi Minh city, Vietnam. Journal of Business and IT. https://doi.org/10.14311/ bit.2018.02.01

Tran, T. T., \& Do, Q. H. (2020). Factors Affecting Job Motivation among Faculty Members: Evidence from Vietnamese Public Universities. Journal of Asian Finance, Economics and Business, 7(9), 603-611. https://doi.org/10.13106/jafeb.2020. vol7.no9.603

Trinh, P. T. T., \& Thanh, N. D. (2017). Development characteristics of SME sector in Vietnam: Evidence from the Vietnam enterprise census 2006-2015. VEPR [Viet Nam Institute for Economic and Policy Research, supported by The Friedrich
Naumann Foundation for Freedom] Working Paper WP-18. Hanoi, Vietnam.

Van den Broeck, A., Vansteenkiste, M., De Witte, H., Soenens, B., \& Lens, W. (2010). Capturing autonomy, competence, and relatedness at work: Construction and initial validation of the Work-related Basic Need Satisfaction scale. Journal of Occupational and Organizational Psychology, 83(4), 9811002.

Venkatesh, B., \& Sharma, A. K. (2015). Interactive motivational concept: a study of motivation among corporate of Bhopal region in India. Journal of Asian Finance, Economics and Business, 2(2), 35-38. https://doi.org/10.13106/jafeb.2015. vol2.no2.35.

Wahyuni, S., Widodo, S. E., \& Retnowati, R. (2016). The Relationship of Interpersonal Communication, Working Motivation and Transformational Leadership to Teachers' Job Satisfaction. dalam International Journal of Managerial Studies and Research, 4(8), 89-93.

Westley, F. R. (1990). Middle managers and strategy: Microdynamics of inclusion. Strategic Management Journal, 11(5), 337-351.

WTO. (2019). World Trade Statistical Review 2019. https://doi. org/10.30875/7195c6e1-en

Yusof, H. S. M., Munap, R., Badrillah, M. I. M., Ab Hamid, N. R., \& Khir, R. M. (2017). The relationship between organizational culture and employee motivation as moderated by work attitude. Journal of Administrative and Business Studies, 3(1), 21-25. 